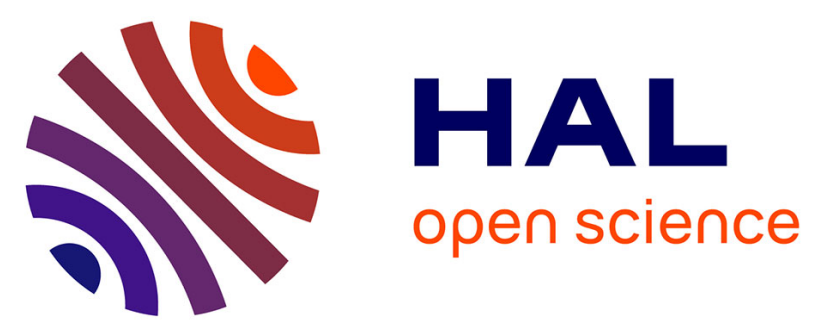

\title{
Comparing the mechanical properties, microstructure, texture and in-vitro degradation behavior of TNTZ/nano-fluorapatite composite and TNTZ bioalloy
} F. Rajabi, A. Zarei-Hanzaki, H.R. R Abedi, A. Safdel, E. Bertrand

\section{- To cite this version:}

F. Rajabi, A. Zarei-Hanzaki, H.R. R Abedi, A. Safdel, E. Bertrand. Comparing the mechanical properties, microstructure, texture and in-vitro degradation behavior of TNTZ/nano-fluorapatite composite and TNTZ bioalloy. Journal of the mechanical behavior of biomedical materials, 2021, 117, pp.104402. 10.1016/j.jmbbm.2021.104402 . hal-03205699

\section{HAL Id: hal-03205699 \\ https://hal.science/hal-03205699}

Submitted on 2 Jul 2021

HAL is a multi-disciplinary open access archive for the deposit and dissemination of scientific research documents, whether they are published or not. The documents may come from teaching and research institutions in France or abroad, or from public or private research centers.
L'archive ouverte pluridisciplinaire HAL, est destinée au dépôt et à la diffusion de documents scientifiques de niveau recherche, publiés ou non, émanant des établissements d'enseignement et de recherche français ou étrangers, des laboratoires publics ou privés. 


\title{
Comparing the mechanical properties, microstructure, texture and in-vitro degradation behavior of TNTZ/nano-fluorapatite composite and TNTZ bioalloy
}

\author{
F. Rajabi ${ }^{\mathrm{a}}$, A. Zarei-Hanzaki ${ }^{\mathrm{a}, *}$, H. R. Abedi ${ }^{\mathrm{b}, *}$, A. Safdel $^{\mathrm{a}}$, E. Bertrand $^{\mathrm{c}}$ \\ ${ }^{a}$ Hot Deformation \& Thermomechanical Processing Laboratory of High Performance Engineering Materials, \\ School of Metallurgy and Materials Engineering, College of Engineering, University of Tehran, Tehran, Iran \\ ${ }^{b}$ School of Metallurgy \& Materials Engineering, Iran University of Science and Technology (IUST), Tehran, Iran \\ ${ }^{c}$ Institut des Matériaux Jean Rouxel (IMN), Université de Nantes, CNRS, 2 rue de la Houssinière, BP 32229 , \\ 44322 Nantes cedex 3, France
}

\begin{abstract}
The present study deals with (i) the fabrication of the composite surface layer of Ti-29Nb-13Ta$4.6 \mathrm{Zr} /$ nano-fluorapatite through friction stir processing, (ii) clarifying the correlation of microstructure and texture with in-vitro degradation behavior and bioactivity of fabricated nanobiocomposite, and (iii) comparing the mechanical and functional properties of nano composite whit those obtained for TNTZ bio-alloy. The results indicated that increasing the number of deformation passes effectively refines the microstructure, leading to the average grain sizes of less than $5 \mu \mathrm{m}$. The texture of the material was also evolved in the presence of the nano particles where the grains reorient along <111> direction in contrast to the $<101>$-oriented grains in the starting microstructure. In-vitro bioactivity of the processed samples was measured after being immersed in simulated body fluid solution for various duration up to 30 days. Enhanced corrosion resistance and bio-mineralization of nanocomposite surface layer was discussed relying on the occurrence of grain refinement, substructure development and evolution of texture components along <101> direction. Assessment of the mechanical properties of the fabricated composites and as-received material also indicated the positive effect of the applied processing route and the presence of nano particles.
\end{abstract}

Keywords: Titanium alloy; Friction Stir Processing; Microstructure; Nanocomposite; Biocompatibility; Corrosion resistance

\footnotetext{
* Corresponding authors

E-mail address: zareih@ut.ac.ir (Abbas Zarei-Hanzaki)

E-mail address: habedi@iust.ac.ir (Hamid Reza Abedi)
} 


\section{Introduction}

Owing to the combination of superior biocompatibility, low corrosion rate, low elastic modulus, high strength, and excellent osseointegration, titanium alloys have drawn much attention in biomedical industry to fabricate orthopedic implants and dental equipment [1-4]. In this respect, the corrosion properties must be assessed comprehensively prior to any in-body applications, because deterioration of corrosion properties and the follow-on metal releasing, results in decreasing biocompatibility and mechanical integrity of the material $[5,6]$. Generally, the rate of corrosion is expected to be higher for a refined structure where the grain boundary is more susceptible to the corrosive environment. This statement is not always true for all types of corrosion, and the rate of local pitting corrosion may be reduced with decreasing grain size. There are also many reports regarding the positive and negative effect of increasing in dislocation density on the corrosion resistance of biomaterials [7-9]. But, it has been well stablished that the passivity and formation of a stable/adherent continuous oxide film over the surface is the main reason for exceptional corrosion behavior of the bio-alloys [10-17]. However, the material which possess excellent corrosion properties may not be a reasonable choice to fabricate a biomedical implant, and the correlated biocompatibility should be precisely examined [18,19].

A specific ceramic material, capable of forming a strong chemical bond with human bones is generally utilized to coat the surface of the metallic bio-material, which is in contact with the living tissues. This treatment is generally required to increase the bioactivity of the metallic surface and therefore enhance the implant osseointegration with the bone tissues [20-23]. Numerous studies have introduced different ceramics to further improve the surface characteristics of the titanium-based orthopedic implants, which mostly point out the "hydroxyapatite (HA)" as the most promising material [24-26]. This bio-ceramic resembles the mineral constituents of the human 
bone and teeth and is also rich of Calcium and Phosphorous, which all lead to a more favorable tissue response by accelerating and enhancing fixation to the hard bone. HA coating acts as a barrier to metallic ion release and simultaneously increases the bone bioactivity due to the present chemical constituents [27]. Cook et al. [28] proved that, by using a coated implant instead of an uncoated one, the bone growth is stimulated, and the adhesion of bone to implant is strengthened. It has been also found that incorporating Fluorine into the mentioned apatite structure would lead to lower dissolution, better protein adsorption, comparable or better cell attachment, and significantly improved alkaline phosphate activity. This combination was named fluoridated hydroxyapatite (FHA) with the chemical composition of $\mathrm{Ca}_{10}\left(\mathrm{PO}_{4}\right)_{6} \mathrm{OH}_{2-\mathrm{x}} \mathrm{F}$, in which " $\mathrm{x}$ " stands for the degree of fluoridation [29].

In the present work, friction stir processing (FSP), as one of the recently developed severe plastic deformation techniques, has been employed to insert the nano-fluorine apatite and make nano-composite surface layer of Ti-29Nb-13Ta-4.6Zr alloy. The adopted experimental material (known as TNTZ [30]) possesses extensive clinical applications due to its considerably low Young's Modulus (60 GPa), non-toxic components [31,32], and excellent corrosion resistance in Hank's physiological solution [33]. In the course of friction stir processing, a cylindrical rotating tool with a small pinhead is inserted and then traveled, thus modifying the structure of the nearsurface layers. [34-36]. The material would experience high amount of strain, strain rate and temperature, and the occurrence of any microstructure evolution (substructure development, grain refinement, phase transformation and second phase redistribution) or texture evolution, are highly probable [37-41]. In this respect, the current work also try to clarify the imperative role of microstructure and texture in improvement of the corrosion resistance, biocompatibility and invitro degradation behavior of the processed Ti-29Nb-13Ta-4.6Zr alloy nano-biocomposite. For 
further clarification, the obtained results have been compared with those obtained for the processed material without nano-powders and also homogenized as-received material.

\section{Experimental procedure}

The experimented alloy was received in as-forged condition holding the nominal chemical composition of $\mathrm{Ti}-27.96 \mathrm{Nb}-11.97 \mathrm{Ta}-5.02 \mathrm{Zr}-0.05 \mathrm{O}-0.01 \mathrm{C}-0.014 \mathrm{~N}$ (wt. \%). In order to eliminate the remained casting defects and segregations, homogenization treatment was performed above the calculated beta transus temperature $\left(\sim 690^{\circ} \mathrm{C}\right)$ at $850^{\circ} \mathrm{C}$ for 45 minutes in a tube furnace containing high purity argon gas [42-44]. The initial microstructure and detailed specifications of the as-received alloy were reported previously by the present authors [45], where it was shown that the material consists of a single $\beta$ phase and the average grain size was estimated to be $64 \pm 1$ $\mu \mathrm{m}$. The annealed material was then cut into $50 \times 25 \times 3 \mathrm{~mm}$ work-pieces using an electro-discharge machine (EDM). A groove having depth and width of $1 \mathrm{~mm}$, was machined out on the top surface of each work-piece. The nano-sized FA powder particles were then inserted into the groove. Fig. 1 shows a schematic view of the FSP processing and the utilized tools to conduct the experiment [46]. The FSP process was carried out in either one pass or three passes under the rotation speed range from 1250 to $2000 \mathrm{rpm}$, at a constant travel speed of $50 \mathrm{~mm} / \mathrm{min}$, and a tilt angle of $1^{\circ}$. A Plexiglas chamber was designed in which argon atmosphere was maintained during the process to shield the material and eliminate the effect of oxidation. The comprehensive details of the processing procedure have been well reported elsewhere [47]. In order to evaluate the corresponding mechanical properties, the flat plate miniaturized tensile specimens, with a thickness of $1 \mathrm{~mm}$ and a gauge dimensions of $16 \times 2.6 \mathrm{~mm}$ were prepared using an EDM in accordance with ASTM E8M, and keeping the aspect ratio. Mechanical response of the treated 
specimens was studied by stress-strain measurements in tensile mode, utilizing a SANTAM STM50 universal testing machine with a load accuracy of $5 \mathrm{~N}$, under the cross-head speed of 0.1 $\mathrm{mm} \cdot \mathrm{min}^{-1}$.

The deformed specimens were cut parallel to the compression axis, and the resulting surfaces were ground by $\mathrm{SiC}$ abrasive paper up to 5000 grit and then polished by $\mathrm{SiO}_{2}$ suspension solution. For scanning electron microscopy observations, these samples were etched using a solution of HF, HNO3, and H2O (5:15:80). Further characterization was conducted on electropolished samples utilizing a scanning electron microscope (SEM) equipped with electron backscattered diffractometer (EBSD).

The corrosion resistance of the as-received and friction stir processed specimens was determined by Electrochemical Impedance Spectroscopy (EIS) analysis. The Solartron 1260 frequency response analyzer was used to assess the frequency responses of the specimens in a simulated body fluid (SBF) solution having a $\mathrm{pH}$ of 6.9. The exact composition of this solution and ion concentrations are represented in Table 1, which confirms the resemblance of the SBF solution and the blood plasma. Each experiment was repeated at $37 \pm 1{ }^{\circ} \mathrm{C}$ on three identical samples to ensure the reliability of the procedure and the accuracy of the calculated mean frequency response. The corrosion resistance of each specimen was measured firstly at the beginning of the experiment and then after 24 and 118 hours, and finally after 30 days. In this regard, a threeelectrode cell was used, in which the sample, the platinum foil, and the saturated calomel electrode (SCE) had acted as the electrode, counter electrode, and reference electrode, respectively.

In order to evaluate the in-vitro bioactivity of the mentioned specimens, samples having a dimension of $10 \times 10 \times 3 \mathrm{~mm}$ were cut from the middle of the stirred zone. To quickly assess the role of mineral phases on the degradation behavior of the samples, the introduced SBF solution 
was used as a mineralization accelerant. Bioactivity of samples was first measured at $37^{\circ} \mathrm{C}$, before immersion and then after 24 hours, 118 hours, and 30 days of immersion in a constant water bath (Bain-Marie bath). Corrosion resistance was measured after removing the samples from the solution, and the deposited phases on the surface of the samples were characterized by SEM and energy dispersive X-ray spectroscopy (EDS). High-resolution X-ray diffraction analysis (PhilipsX'pert, rotating copper anode, Netherlands) was carried out using $\mathrm{CuK}_{\alpha}$ radiation $(\lambda=1.5406 \AA)$ to identify the constitutive phases in the microstructures.

\section{Results and discussion}

Fig. 2 illustrates the inverse pole figure (IPF) maps of the stirring zones (SZ) of the specimens processed through 1 and 3 passes of FSP. The average grain size and the percentage of LAGBs for each sample are reported in Table 2. All microstructures exhibit numerous subgrains and a high frequency of low angle grain boundaries (LAGB), which together point to the fact that all samples have experienced continuous dynamic recrystallization (CDRX) as the dominant restoration mechanism during FSP [48]. Firstly, a dramatic decrease in average grain size from 64 to $\sim 10 \mu \mathrm{m}$ is observed for the FSPed specimens in comparison with the homogenized one. As was mentioned earlier, FSP, as a severe plastic deformation technique, is capable to significantly decrease the average grain size of the material, due to the occurrence of restoration mechanisms. Moreover, for both materials after either 1 pass or 3 passes of FSP, a reduction in grain size is evident when the nFA particles were used. Incorporating nFA particles led to the grain size reduction from 9.8 to $6.7 \mu \mathrm{m}$, and from 11.5 to $5.9 \mu \mathrm{m}$ for specimens processed by 1 or 3 passes, respectively. This fact shows how nanoparticles are capable to further decrease the average grain size of the material during severe plastic deformation. Surprisingly, the average grain size of $3 P$ 
was measured to be around $11.5 \mu \mathrm{m}$, which is higher than that of for $1 P$ sample. Evidently, Grain growth has occurred for the $3 P$ sample as a result of being in high temperatures for a longer period of time. Fig. 3 demonstrates the inverse pole figures (IPFs) of the homogenized and FSPed samples, which represents the statistical distribution of the crystallographic planes parallel to the sample's surface. As can be seen in Fig. 3(a) for the homogenized sample, there is a slight accumulation of crystallographic orientations toward the intrinsic <101> directions. After FSP, this texture is strengthened, and according to Fig. 3(c, e), for $1 P$ and $3 P$ sample, most of the crystallographic planes are oriented toward the same direction. On the other hand, when nFA particles are used, as is depicted for $1 P-n F A$ and $3 P-n F A$ samples in Fig. 3(b, d), texture is also greatly affected. In these samples, the majority of the planes' orientations have shifted toward $<111>$ directions. The nFA particles pinned the grain boundaries, which resulted the grain growth to occur only along a preferred direction. On the other hand, these particles contributed to the nucleation of many sub-crystals, and as a result, numerous LAGBs were formed. Therefore, the addition of these particles made the crystallographic orientation of the TNTZ alloy to change from $<101>$ toward <110> directions [49].

Mechanical behavior of the samples was examined, and the resulting engineering stress vs. engineering strain curves are depicted in Fig. 4. The value of ultimate tensile strength (UTS), ductility and yield stress were extracted from this figure and are summarized in Fig. 4. As it can be deduced from this figure, nearly all the mentioned parameters are higher in FSPed samples in comparison to the homogenized one. As was discussed earlier, FSP has the potential to evolve the microstructure, in which CDRX and grain refinement play major roles. To this end, higher UTS and yield stress is attributed to a more refined microstructure and the dramatic decrease in grain size (Table 2). It has been well established that by conducting different SPD techniques, not only 
the strength of the material is increased, but also the ductility of the material is either improved or at least is not deteriorated [8]. In this study, ductility has also been increased for nearly all the processed specimens. However, for $1 P$ specimen, as is shown in Fig. 4(b), which had a significantly higher UTS (Fig, 4a), lower ductility was recorded which is believed to be due to the high density of the present dislocations and the heterogeneous strain accumulation in FSP. Table. 3 summarizes the results of the evaluation of the mechanical properties for homogenized, FSP, and FSP-nFA. It is worth mentioning that the incorporated particles produced many dislocations and as a result, generated a high quantity of barriers to limit the movement of dislocations, thus significantly improving the mechanical strength of the composites. The nano particles were homogeneously distributed in the matrix, which increased the strength of the matrix [49].

On the contrary to what was expected 3P sample exhibits the highest mechanical strength, as opposed to those samples that had ceramic nFA particles inside them. This observation can be justified by referring to the acquired X-ray diffraction patterns (Fig. 5) and the presence of $\alpha$ and $\omega$ phase in different samples. To this end, highest yield stress was observed for 3P sample due to the highest percentage of $\alpha$ phase in structure. With increasing the number of passes, $\beta$ and $\alpha^{\prime \prime}$ peaks were changed and $\beta$ phase peaks were abated and then disappeared

The SEM image and the corresponding EDS analysis of the homogenized sample after immersion in the SBF solution for 30 days are both represented in Fig. 6. EDS analysis was used to identify the relative elemental composition of the material and compare the atomic percentage of each elements. Hence, the obtained EDS data can be used to compare the level of mineralization for all samples after being immersed in the SBF solution for different intervals of time. In this figure, sodium and chlorine rich phases have been identified by EDS analysis. As was mentioned earlier, $1 \times 1 \mathrm{~mm}$ grooves were machined out of the work-pieces and then were filled with $\mathrm{nFA}$ 
powder. However, the width of the nFA powder distribution after FSP would be nearly equal to the width of the stirring zone area, which is attributed to the characteristics of the material flow during FSP [50]. As the FSP tool moves in the transverse direction, the material captured in the swirl zone beneath the tool pin undergoes a vortex flow around the pin from the front to the rear in the extrusion zone and this result in a non-uniform depth of the processed zone [51,52].

Fig. 7 shows the SEM micrographs of the differently processed specimens after being immersed in the SBF solution for 118 hours. White deposited phases are present in the materials processed with nFA particles, which consists of $\mathrm{Ti}, \mathrm{Nb}, \mathrm{Ta}, \mathrm{Zr}, \mathrm{Ca}, \mathrm{P}, \mathrm{Na}$ and $\mathrm{Cl}$ due to the composition of the SBF solution and also the present FA coating. In other words, $\mathrm{Ti}, \mathrm{Nb}, \mathrm{Ta}$, and $\mathrm{Zr}$ are observed due to the chemical composition of the sample, while for $\mathrm{Ca}, \mathrm{P}, \mathrm{Na}$, and $\mathrm{Cl}$, the source is either the SBF solution and/or FA coating. Fig. 8 reveals the microstructure of the same specimens after 30 days of immersion and by comparing Fig. 7 and Fig. 8, it can be concluded that white spherical particles are increased as a result of longer immersion intervals in SBF solution. Therefore, a considerable number of white particles were observed on the surface of the processed specimens after 30 days.

EDS analysis was performed on one of these particles using 1P-nFA sample, and the result which is represented in Fig. 9 confirms that the chemical composition of these spheres is identical to hydroxyapatite. Table 4 summarized the result of the EDS analysis, which was performed on all the FSPed specimens, revealing the percentage of each element in each sample. Firstly, higher percentage of $\mathrm{Ca}$ and $\mathrm{P}$ was recorded in those samples that were processed with $\mathrm{nFA}$ particles. The $\mathrm{Ca} / \mathrm{P}$ ratio was measured, which is believed to be an indication of the bioactivity of the material, and the results show that using nFA particles during FSP would result in highly bioactive composite parts. As it was presented in Fig. 7 and Fig. 8, utilizing nFA particles resulted in 
formation of a thick and dense apatite on the surface (spherical white particles), which is expected to enhance the bioactivity. In other words, nFA particles acted as nucleation sites in the SBF solution, which stimulated the process of apatite crystallization [53]. Overall, heterogeneous apatite crystallization was accelerated due to two main reasons: (1) the presence of nFA particles, which acted as nucleation sites, and (2) providing a surface with the optimum interfacial energy to initiate the nucleation $[54,55]$. However, it is worth to mention that as opposed to coating, in this study, the entire surface of the material could not be covered by HA.

Different impedance spectra were obtained for different exposure times and then various electrical circuit models were utilized to find the best equivalent circuit and it was found that best fitting is achieved when the given circuit model in Fig. 10 is utilized. According to this figure, $R_{s}$ is the resistance of the electrolyte solution and the electrical leads, $\mathrm{CPE}_{\mathrm{p}}$ is the capacitance of the intact (non-defective) coating layer, $\mathrm{R}_{\mathrm{p}}$ is the charge transfer resistance associated with the penetration of the electrolyte throughout the present pores in the coating, $R_{\mathrm{ct}}$ is the polarization resistance of the substrate, and $\mathrm{CPE}_{\mathrm{dl}}$ is the capacitance of the interface layer between the substrate and the electrolyte.

It must be noticed that the elements represented in circuits as capacitors $C_{p}$ and $C_{p . d l}$ were fitted as constant phase elements. This is a general diffusion related to element $\mathrm{Q}$ which accounts for deviations from idea dielectric behavior related to surface inhomogeneity or current leakage in the interface [56].

The acquired impedance spectra of the homogenized and FSPed samples after being immersed in SBF solution for different duration of times are shown in Fig. 11. $R_{s}, R_{p}$, and CPE values were measured accordingly and are presented in Table 5 for each sample. $R_{p}$ indicates the corrosion resistance for each sample and as is evident, the corrosion rate is decreased in FSPed 
samples with nFA particles, compared to the other samples with measured corrosion resistance (Rp), is due to the development of a quick passive layer [57], and reduced intensity of galvanic couple between gain interior and grain boundary as the grain size becomes smaller [58]. An equivalent circuit consists of various arrangements of resistances, capacitors, and other circuit elements, and provides the most relevant corrosion parameters applicable to the substrate/electrolyte system.

The FA layer acts as a barrier to the transport of electrons and ions between the substrate and the electrolyte, thus reducing the electrochemical reaction rate. The improved corrosion resistance of the HA coated Ti6Al4V is ascribed to the combined effect of the semi-insulating HA coating and $\mathrm{TiO}_{2}$ [59]. In the other investigated, the immersion of Ti samples in HBSS results in spontaneous nucleation of octacalcium phosphate +HAP on top of the 'natural' or 'spontaneous' oxide-hydroxide film formed on the surface in contact with moist air or water [60].

Many studies believe that the main factor which affects the corrosion behavior of a sample is grain size, and the importance of other factors has been overlooked. Texture of the material, is severely influenced by the processing scheme and FSP as an SPD route, has a huge impact on the texture of the material [41]. Some studies, on the other hand, correlated the texture and the corrosion behavior of some materials. Therefore, two factors could simultaneously govern the corrosion process; (1) grain size, and (2) texture of the material. The corrosion behavior of the samples was correlated to the observed texture (Fig. 3) for each specimen and it was found that for any specimen the presence of a preferential texture along the (111) direction could lead to higher corrosion resistance. Similar results were reported for stainless steel 316L, in which the highest corrosion resistance was observed for textured samples along the (111) direction in a chloride containing solution [61]. 
Fig. 12 and Fig. 13 exhibited both Bode amplitude and phase angle plots. The bode plots indicated for the investigation of changes in the electrochemical characteristics of the system. Changes are less marked with time elapsing, and after 30 days exposure, an almost stationary behavior was reached. These results exhibit that the electrochemical properties of the film change with exposure time. Fig. 14 shows that the corrosion rate of samples is very low. As is seen, the samples don't lose weight and a little increase in weight.

\section{Conclusion}

TNTZ biomedical titanium alloy, was processed via FSP in different passes with or without the presence of fluorapatite nano particles. The achieved microstructure, texture and mechanical properties of these fabricated alloys were compared and correlated to their in-vitro degradation behavior. The results are summarized as follows:

- The presence of nFA particles caused an effective texture modification, and the orientation of the grains shifted from <101> directions toward <111> during friction stir processing.

- FSPed-TNTZ-nFA composite demonstrated excellent bioactivity compared to FSPed-TNTZ samples and homogenized samples due to the early formation of mineral phases (apatite) over the surface. The controlled localized degradation was led to the enhanced corrosion resistance of TNTZ-nFA composites.

- The formed apatite layer on the surface and the resultant precipitate layer acted as barriers to metal dissolution are the main reason for increased corrosion resistance. This improvement was pronounced for immersed samples in SBF solution after 30 days. 
- The improved corrosion behavior of the fabricated composites is mainly attributed to the grain refinement, substructure development, texture evolution, apatite layer formation and subsequent homogenous dispersion of nano particles.

- The 3pass-FSP-nFA sample exhibited the highest corrosion resistance in the SBF solution, due to the intensified texture component and grain orientations along the $<111>$ direction and also the formed apatite layer over the surface.

\section{References}

[1] M. Geetha, A.K. Singh, R. Asokamani, A.K. Gogia, Ti based biomaterials, the ultimate choice for orthopaedic implants - A review, Prog. Mater. Sci. 54 (2009) 397-425. doi:http://doi.org/10.1016/j.pmatsci.2008.06.004.

[2] M.A. Kalaie, A. Zarei-Hanzaki, M. Ghambari, P. Dastur, J. Málek, E. Farghadany, The effects of second phases on superelastic behavior of TNTZ bio alloy, Mater. Sci. Eng. A. 703 (2017) 513520. doi:https://doi.org/10.1016/j.msea.2017.07.053.

[3] A. Maghsoudlou, A. Zarei-Hanzaki, H.R. Abedi, A. Barabi, F. Pilehva, D. Dietrich, T. Lampke, The room temperature tensile deformation behavior of thermomechanically processed $\beta$ metastable Ti-Nb-Ta-Zr bio-alloy: the role of deformation-induced martensite, Mater. Sci. Eng. A. 738 (2018) 15-23. doi:https://doi.org/10.1016/j.msea.2018.09.038.

[4] A. Safdel, A. Zarei-Hanzaki, A. Shamsolhodaei, P. Krooß, T. Niendorf, Room temperature superelastic responses of NiTi alloy treated by two distinct thermomechanical processing schemes, Mater. Sci. Eng. A. 684 (2017) 303-311. doi:https://doi.org/10.1016/j.msea.2016.12.047.

[5] G. Lütjering, u. JC Williams: Titanium, (2007).

[6] A.S. Anoushe, A. Zarei-Hanzaki, H.R. Abedi, A. Barabi, C. Huang, F. Berto, On the microstructure evolution during isothermal low cycle fatigue of $\beta$-annealed Ti-6242S titanium alloy: Internal damage mechanism, substructure development and early globularization, Int. J. Fatigue. 116 (2018) 592-601. doi:https://doi.org/10.1016/j.ijfatigue.2018.07.014.

[7] K.S. Suresh, M. Geetha, C. Richard, J. Landoulsi, H. Ramasawmy, S. Suwas, R. Asokamani, Effect of equal channel angular extrusion on wear and corrosion behavior of the orthopedic Ti$13 \mathrm{Nb}-13 \mathrm{Zr}$ alloy in simulated body fluid, Mater. Sci. Eng. C. 32 (2012) 763-771. doi:https://doi.org/10.1016/j.msec.2012.01.022.

[8] D. Raducanu, E. Vasilescu, V.D. Cojocaru, I. Cinca, P. Drob, C. Vasilescu, S.I. Drob, Mechanical and corrosion resistance of a new nanostructured $\mathrm{Ti}-\mathrm{Zr}-\mathrm{Ta}-\mathrm{Nb}$ alloy, J. Mech. Behav. Biomed. Mater. 4 (2011) 1421-1430. doi:https://doi.org/10.1016/j.jmbbm.2011.05.012.

[9] W.Y. Guo, J. Sun, J.S. Wu, Effect of deformation on corrosion behavior of Ti-23Nb-0.7Ta-2ZrO alloy, Mater. Charact. 60 (2009) 173-177. doi:https://doi.org/10.1016/j.matchar.2008.08.006.

[10] H. Krawiec, V. Vignal, J. Loch, P. Erazmus-Vignal, Influence of plastic deformation on the microstructure and corrosion behaviour of $\mathrm{Ti}-10 \mathrm{Mo}-4 \mathrm{Zr}$ and $\mathrm{Ti}-6 \mathrm{Al}-4 \mathrm{~V}$ alloys in the Ringer's solution at $37^{\circ} \mathrm{C}$, Corros. Sci. 96 (2015) 160-170. doi:https://doi.org/10.1016/j.corsci.2015.04.006.

[11] M. Atapour, A.L. Pilchak, G.S. Frankel, J.C. Williams, Corrosion behavior of $\beta$ titanium alloys for biomedical applications, Mater. Sci. Eng. C. 31 (2011) 885-891.

doi:https://doi.org/10.1016/j.msec.2011.02.005. 
[12] A.M. Fekry, R.M. El-Sherif, Electrochemical corrosion behavior of magnesium and titanium alloys in simulated body fluid, Electrochim. Acta. 54 (2009) 7280-7285.

doi:https://doi.org/10.1016/j.electacta.2009.07.047.

[13] M.C. García-Alonso, L. Saldaña, C. Alonso, V. Barranco, M.A. Muñoz-Morris, M.L. Escudero, In situ cell culture monitoring on a $\mathrm{Ti}-6 \mathrm{Al}-4 \mathrm{~V}$ surface by electrochemical techniques, Acta Biomater. 5 (2009) 1374-1384. doi:https://doi.org/10.1016/j.actbio.2008.11.020.

[14] R.W.-W. Hsu, C.-C. Yang, C.-A. Huang, Y.-S. Chen, Electrochemical corrosion properties of Ti6Al-4V implant alloy in the biological environment, Mater. Sci. Eng. A. 380 (2004) 100-109. doi:https://doi.org/10.1016/j.msea.2004.03.069.

[15] H.-H. Huang, Effect of fluoride and albumin concentration on the corrosion behavior of Ti-6Al4V alloy, Biomaterials. 24 (2003) 275-282. doi:https://doi.org/10.1016/S0142-9612(02)00315-0.

[16] S. Tamilselvi, V. Raman, N. Rajendran, Corrosion behaviour of Ti-6Al-7Nb and Ti-6Al-4V ELI alloys in the simulated body fluid solution by electrochemical impedance spectroscopy, Electrochim. Acta. 52 (2006) 839-846. doi:https://doi.org/10.1016/j.electacta.2006.06.018.

[17] S. Karimi, T. Nickchi, A. Alfantazi, Effects of bovine serum albumin on the corrosion behaviour of AISI 316L, Co-28Cr-6Mo, and Ti-6Al-4V alloys in phosphate buffered saline solutions, Corros. Sci. 53 (2011) 3262-3272. doi:https://doi.org/10.1016/j.corsci.2011.06.009.

[18] I. Gurappa, Characterization of different materials for corrosion resistance under simulated body fluid conditions, Mater. Charact. 49 (2002) 73-79. doi:http://doi.org/10.1016/S10445803(02)00320-0.

[19] M. Donachie, Biomedical alloys, Adv. Mater. Process. 154 (1998) 63-65.

[20] T.R. Rautray, R. Narayanan, T. Kwon, K. Kim, Surface modification of titanium and titanium alloys by ion implantation, J. Biomed. Mater. Res. Part B Appl. Biomater. 93 (2010) 581-591.

[21] A. Carradó, Structural, microstructural, and residual stress investigations of plasma-sprayed hydroxyapatite on Ti-6Al-4 V, ACS Appl. Mater. Interfaces. 2 (2010) 561-565.

[22] K.W.K. Yeung, R.W.Y. Poon, P.K. Chu, C.Y. Chung, X.Y. Liu, W.W. Lu, D. Chan, S.C.W. Chan, K.D.K. Luk, K.M.C. Cheung, Surface mechanical properties, corrosion resistance, and cytocompatibility of nitrogen plasma-implanted nickel-titanium alloys: A comparative study with commonly used medical grade materials, J. Biomed. Mater. Res. Part A An Off. J. Soc. Biomater. Japanese Soc. Biomater. Aust. Soc. Biomater. Korean Soc. Biomater. 82 (2007) 403-414.

[23] N. Coen, M.A. Kadhim, E.G. Wright, C.P. Case, C.E. Mothersill, Particulate debris from a titanium metal prosthesis induces genomic instability in primary human fibroblast cells, Br. J. Cancer. 88 (2003) 548-552.

[24] C.L. Tisdel, V.M. Goldberg, J.A. Parr, J.S. Bensusan, L.S. Staikoff, S. Stevenson, The influence of a hydroxyapatite and tricalcium-phosphate coating on bone growth into titanium fiber-metal implants., J. Bone Joint Surg. Am. 76 (1994) 159-171.

[25] A. Moroni, V.L. Caja, C. Sabato, E.L. Egger, F. Gottsauner-Wolf, E.Y.S. Chao, Bone ingrowth analysis and interface evaluation of hydroxyapatite coated versus uncoated titanium porous bone implants, J. Mater. Sci. Mater. Med. 5 (1994) 411-416.

[26] C.P.A.T. Klein, P. Patka, J.G.C. Wolke, J.M.A. de Blieck-Hogervorst, K. de Groot, Long-term in vivo study of plasma-sprayed coatings on titanium alloys of tetracalcium phosphate, hydroxyapatite and $\alpha$-tricalcium phosphate, Biomaterials. 15 (1994) 146-150. doi:https://doi.org/10.1016/0142-9612(94)90264-X.

[27] M.H. Fathi, A. Hanifi, Evaluation and characterization of nanostructure hydroxyapatite powder prepared by simple sol-gel method, Mater. Lett. 61 (2007) 3978-3983. doi:https://doi.org/10.1016/j.matlet.2007.01.028.

[28] S.D. Cook, K.A. Thomas, J.E. Delton, T.K. Volkman, T.S. Whitecloud III, J.F. Key, Hydroxylapatite coating of porous implants improves bone ingrowth and interface attachment strength, J. Biomed. Mater. Res. 26 (1992) 989-1001.

[29] M.H. Fathi, E.M. Zahrani, Fabrication and characterization of fluoridated hydroxyapatite nanopowders via mechanical alloying, J. Alloys Compd. 475 (2009) 408-414. 
doi:https://doi.org/10.1016/j.jallcom.2008.07.058.

[30] Y. Okazaki, A New Ti-15Zr-4Nb-4Ta alloy for medical applications, Curr. Opin. Solid State Mater. Sci. 5 (2001) 45-53. doi:https://doi.org/10.1016/S1359-0286(00)00025-5.

[31] Y. Tanaka, M. Nakai, T. Akahori, M. Niinomi, Y. Tsutsumi, H. Doi, T. Hanawa, Characterization of air-formed surface oxide film on $\mathrm{Ti}-29 \mathrm{Nb}-13 \mathrm{Ta}-4.6 \mathrm{Zr}$ alloy surface using XPS and AES, Corros. Sci. 50 (2008) 2111-2116. doi:https://doi.org/10.1016/j.corsci.2008.06.002.

[32] Y. Okazaki, E. Nishimura, H. Nakada, K. Kobayashi, Surface analysis of Ti-15Zr-4Nb-4Ta alloy after implantation in rat tibia, Biomaterials. 22 (2001) 599-607. doi:https://doi.org/10.1016/S0142-9612(00)00221-0.

[33] M. Karthega, V. Raman, N. Rajendran, Influence of potential on the electrochemical behaviour of $\beta$ titanium alloys in Hank's solution, Acta Biomater. 3 (2007) 1019-1023.

doi:https://doi.org/10.1016/j.actbio.2007.02.009.

[34] V. V Stolyarov, Y.T. Zhu, I. V Alexandrov, T.C. Lowe, R.Z. Valiev, Grain refinement and properties of pure Ti processed by warm ECAP and cold rolling, Mater. Sci. Eng. A. 343 (2003) 43-50. doi:https://doi.org/10.1016/S0921-5093(02)00366-0.

[35] H. Garbacz, M. Pisarek, K.J. Kurzydłowski, Corrosion resistance of nanostructured titanium, Biomol. Eng. 24 (2007) 559-563. doi:https://doi.org/10.1016/j.bioeng.2007.08.007.

[36] R.Z. Valiev, R.K. Islamgaliev, I. V Alexandrov, Bulk nanostructured materials from severe plastic deformation, Prog. Mater. Sci. 45 (2000) 103-189.

[37] R.O. Kaibyshev, I.A. Mazurina, D.A. Gromov, Mechanisms of grain refinement in aluminum alloys in the process of severe plastic deformation, Met. Sci. Heat Treat. 48 (2006) 57-62. doi:10.1007/s11041-006-0044-8.

[38] Y. Huang, F.J. Humphreys, Transient dynamic recrystallization in an aluminium alloy subjected to large reductions in strain rate, Acta Mater. 45 (1997) 4491-4503. doi:http://dx.doi.org/10.1016/S1359-6454(97)00140-7.

[39] H. Khatami-hamedani, A. Zarei-hanzaki, M. Ghambari, A. Mohamadizadeh, R. Jafari, M. Moallemi, Toward Unraveling the High Temperature Microstructure Processing Properties Relationship in a Ni-Free High Nitrogen Bearing Duplex Stainless Steel, 1700532 (2018) 1-10. doi:10.1002/srin.201700532.

[40] J.A. del Valle, M.T. Pérez-Prado, J.R. Bartolomé, F. Penalba, O.A. Ruano, Grain refinement in a Mg AZ91 alloy via large strain hot rolling, Mater. Trans. 44 (2003) 2625-2630.

[41] A. Salandari-Rabori, A. Zarei-Hanzaki, H.R. Abedi, J.S. Lecomte, H. Khatami-Hamedani, Micro and macro texture evolution during multiaxial forging of a WE43 magnesium alloy, J. Alloys Compd. 739 (2018) 249-259. doi:https://doi.org/10.1016/j.jallcom.2017.12.181.

[42] S.W. Xin, Y.Q. Zhao, Y.F. Lu, Q. Li, H.Y. Yang, Role of grain boundaries in the high temperature performance of a highly stabilized beta titanium alloy I: Thermal stability, Mater. Sci. Eng. A. 559 (2013) 1-6.

[43] Q. Wei, L. Wang, Y. Fu, J. Qin, W. Lu, D. Zhang, Influence of oxygen content on microstructure and mechanical properties of Ti--Nb--Ta--Zr alloy, Mater. Des. 32 (2011) 2934-2939.

[44] Y.Q. Zhao, S.W. Xin, W.D. Zeng, Effect of major alloying elements on microstructure and mechanical properties of a highly $\beta$ stabilized titanium alloy, J. Alloys Compd. 481 (2009) 190194.

[45] F. Rajabi, A.Z. Hanzaki, H.R. Abedi, E. Farghadany, Corrosion behavior of thermo-mechanically processed biomedical Ti-29Nb-13Ta-4.6Zr, J. Alloys Compd. 725 (2017) 23-31. doi:https://doi.org/10.1016/j.jallcom.2017.04.319.

[46] S. Mironov, Y.S. Sato, H. Kokawa, Microstructural evolution during friction stir-processing of pure iron, Acta Mater. 56 (2008) 2602-2614. doi:http://dx.doi.org/10.1016/j.actamat.2008.01.040.

[47] M.H. Razmpoosh, A. Zarei-Hanzaki, A. Imandoust, Effect of the Zener-Hollomon parameter on the microstructure evolution of dual phase $\{$ TWIP \} steel subjected to friction stir processing, Mater. Sci. Eng. A. 638 (2015) 15-19. doi:http://doi.org/10.1016/j.msea.2015.04.022.

[48] F. Rajabi, A.Z. Hanzaki, H.R. Abedi, H. Hoseiny, A. Najdahmadi, E. Bertrand, Microstructure 
evolution and corrosion behavior of Ti-29Nb-13Ta-4.6Zr nano-biocomposite fabricated by friction stir processing in simulated body fluid solution, Mater. Res. Express. 6 (2019) 105414. doi:10.1088/2053-1591/ab3f08.

[49] Y. Yang, Y. Cheng, S. Peng, L. Xu, C. He, F. Qi, M. Zhao, C. Shuai, Microstructure evolution and texture tailoring of reduced graphene oxide reinforced Zn scaffold, Bioact. Mater. 6 (2021) 12301241. doi:https://doi.org/10.1016/j.bioactmat.2020.10.017.

[50] R.S. Mishra, Z.Y. Ma, Friction stir welding and processing, Mater. Sci. Eng. R Reports. 50 (2005) $1-78$.

[51] W.J. Arbegast, A flow-partitioned deformation zone model for defect formation during friction stir welding, Scr. Mater. 58 (2008) 372-376.

[52] W.J. Arbegast, Modeling friction stir joining as a metalworking process, Hot Deform. Alum. Alloy. III. (2003) 313-327.

[53] M. Bohner, J. Lemaitre, Can bioactivity be tested in vitro with SBF solution?, Biomaterials. 30 (2009) 2175-2179. doi:https://doi.org/10.1016/j.biomaterials.2009.01.008.

[54] H.-M. Kim, T. Himeno, M. Kawashita, T. Kokubo, T. Nakamura, The mechanism of biomineralization of bone-like apatite on synthetic hydroxyapatite: an in vitro assessment, J. R. Soc. Interface. 1 (2004) 17-22.

[55] J.A. Juhasz, S.M. Best, A.D. Auffret, W. Bonfield, Biological control of apatite growth in simulated body fluid and human blood serum, J. Mater. Sci. Mater. Med. 19 (2008) 1823-1829.

[56] J. Pan, D. Thierry, C. Leygraf, Electrochemical and XPS studies of titanium for biomaterial applications with respect to the effect of hydrogen peroxide, J. Biomed. Mater. Res. 28 (1994) $113-122$.

[57] G. Ben Hamu, D. Eliezer, L. Wagner, The relation between severe plastic deformation microstructure and corrosion behavior of AZ31 magnesium alloy, J. Alloys Compd. 468 (2009) 222-229.

[58] G.R. Argade, S.K. Panigrahi, R.S. Mishra, Effects of grain size on the corrosion resistance of wrought magnesium alloys containing neodymium, Corros. Sci. 58 (2012) 145-151.

[59] G.H.I.M. Walenkamp, F.C. Bakker, Biomaterials in surgery, Georg Thieme Verlag, 1998.

[60] J.C. Wataha, Materials for endosseous dental implants, J. Oral Rehabil. 23 (1996) 79-90.

[61] A. Shahryari, J.A. Szpunar, S. Omanovic, The influence of crystallographic orientation distribution on 316LVM stainless steel pitting behavior, Corros. Sci. 51 (2009) 677-682.

\section{Figures}

Fig. 1. Schematic figure of FSP processing.

Fig. 2. EBSD inverse pole figure maps of the stirring zone of sample (a) 1P-nFA, (b) 1P, (C) 3P-nFA, and (d) $3 \mathrm{P}$.

Fig. 3. Inverse pole figures of the TNTZ samples representing texture for (a) Homogenized, (b) 1P-nFA (c) 1P, (d) 3P-nFA, and (e) 3P sample.

Fig. 4. Engineering stress versus engineering strain tensile curves for the homogenized and the FSPed specimens. Mechanical characteristics for homogenized, FSP and FSP-nFA Ti-29-Nb-13Ta-4.6Zr samples. (a) Ultimate tensile strength, (b) ductility and (c) yield stress. 
Fig. 5. X-ray diffraction patters of the FSPed samples.

Fig. 6. The SEM micrograph and the corresponding EDS analysis of the homogenized sample after immersion in SBF for 30 days.

Fig. 7. The SEM micrograph of the processed specimens, (a) 1P-nFA, (b) 3P-nFA, (c) 1P and (d) 3P, after being immersed in SBF solution for 118 hours.

Fig. 8. The SEM micrograph of the processed specimens, (a) 1P-nFA, (b) 3P-nFA, (c) 1P and (d) 3P, after being immersed in SBF solution for 30 days.

Fig. 9. The SEM micrograph and EDS analysis of the 1P-nFA sample after FSP and immersion in SBF solution for 30 days.

Fig. 10. The equivalent electrical circuit (EEC) without (a) and with (b) considering the possible formation of protective layer.

Fig. 11. The Nyquist representation of EIS spectra recorded in neutral SBF solution $\left(37^{\circ} \mathrm{C}\right)$ after Invitro test for the homogenized, FSP and FSP-nFA processed Ti-29-Na-13Ta-4.6Zr alloy, after immersion for (a) 15 min, (b) $24 \mathrm{~h}$, (c) $118 \mathrm{~h}$ and (d) 30 days.

Fig. 12. The Bode representation of EIS spectra for the homogenized, FSP and FSP-nFA processed Ti29Na-13Ta-4.6Zr alloy after immersion in SBF solution for (a) $15 \mathrm{~min}$, (b) $24 \mathrm{~h}$, (c) $118 \mathrm{~h}$ and (d) 30 days.

Fig. 13. The Phase representation of EIS spectra for the homogenized, FSP and FSP-nFA processed Ti29Na-13Ta-4.6Zr alloy after immersion for (a) $15 \mathrm{~min}$, (b) $24 \mathrm{~h}$, (c) $118 \mathrm{~h}$ and (d) 30 day.

Fig. 14. The diagram of changed weight after 30 days immersion in SBF.

\section{Tables}

Table 1. Ion concentrations of the Stimulated Body Fluid (SBF) Solution

Table 2. The average grain size and the percentage of LAGB in the processed samples

Table 3. Mechanical properties of the homogenized, FSPed and FSP-nFA Ti-29-Nb-13Ta-4.6Zr samples.

Table 4. EDS analysis of the corrosion products on the surface of samples immersed in SBF after 30 days

Table 5. Electrical equivalent circuit (EEC) component values obtained by modeling the experimental Electrochemical Impedance Spectroscopy (EIS) data for samples after immersion in SBF solution for different durations. 
Table 1. Ion concentrations of the Stimulated Body Fluid (SBF) Solution

\begin{tabular}{|c|c|c|}
\hline & \multicolumn{2}{|c|}{ Ion concentrations (mM) } \\
\hline Ion & Blood Plasma & SBF Solution \\
\hline $\mathbf{N a}^{+}$ & 142 & 142 \\
\hline $\mathbf{K}^{+}$ & 5 & 5 \\
\hline $\mathbf{M g}^{2+}$ & 1.5 & 1.5 \\
\hline $\mathbf{C a}^{2+}$ & 2.5 & 2.5 \\
\hline $\mathbf{C l}^{-}$ & 103 & 147.8 \\
\hline $\mathbf{H C O}_{3}{ }^{-}$ & 27 & 4.2 \\
\hline $\mathbf{H P O}_{4}{ }^{2-}$ & 1.0 & 1.0 \\
\hline $\mathbf{S O}_{4}{ }^{2-}$ & 0.5 & 0.5 \\
\hline $\mathbf{p H}^{-}$ & $7.2-7.4$ & 7.4 \\
\hline
\end{tabular}


Table 2. The average grain size and the percentage of LAGB in the processed samples

\begin{tabular}{|c|c|c|}
\hline & $\begin{array}{c}\text { Average grain size } \\
(\boldsymbol{\mu m})\end{array}$ & $\begin{array}{c}\text { LAGB Frequency } \\
(\boldsymbol{\%})\end{array}$ \\
\hline Homogenized & $64 \pm 1$ & - \\
\hline $\boldsymbol{1 P}$ & $9.8 \pm 1$ & 80 \\
\hline $\boldsymbol{1 P}-\boldsymbol{n} \boldsymbol{F A}$ & $6.7 \pm 1$ & 88 \\
\hline 3P & $11.5 \pm 2$ & 74 \\
\hline 3P-nFA & $5.9 \pm 1$ & 90 \\
\hline
\end{tabular}


Table 3. Mechanical properties of the homogenized, FSPed and FSP-nFA Ti-29-Nb-13Ta-4.6Zr samples.

\begin{tabular}{|c|c|c|c|}
\hline & UTS (MPa) & Ductility (\%) & Yield Stress (MPa) \\
\hline Homogenized & 549 & 33 & 276 \\
\hline 1P & 760 & 31 & 354 \\
\hline 1P-nFA & 600 & 38 & 384 \\
\hline 3P & 628 & 36 & 422 \\
\hline 3P-nFA & 624 & 38 & 391 \\
\hline
\end{tabular}


Table 4. EDS analysis of the corrosion products on the surface of samples immersed in SBF after 30 days

\begin{tabular}{|c|c|c|c|c|c|c|c|c|c|c|}
\hline $\begin{array}{c}\text { Elements } \\
\text { (at \%) }\end{array}$ & $\mathbf{C}$ & $\mathbf{O}$ & $\mathbf{T i}$ & $\mathbf{N b}$ & $\mathbf{P}$ & $\mathbf{N a}$ & $\mathbf{C l}$ & $\mathbf{C a}$ & $\mathbf{K}$ & $\mathbf{C a} / \mathbf{P}$ \\
\hline $\mathbf{1 P}$ & 6.7 & 22.62 & 28.03 & 12.4 & 3.71 & - & - & 4.01 & - & 1.08 \\
\hline $\mathbf{1 P - n F A}$ & 22.68 & 28.99 & 13.64 & 6.35 & 4.43 & 5.41 & 6.09 & 9.30 & - & 2.09 \\
\hline 3P & 11.74 & 29.99 & 33.95 & 16.24 & 3.72 & 0.31 & - & 3.31 & - & 0.88 \\
\hline 3P-nFA & 21.78 & 35.06 & 5.03 & 4.07 & 5.64 & 4.65 & 5.75 & 13.48 & 0.62 & 2.39 \\
\hline
\end{tabular}


Table 5. Electrical equivalent circuit (EEC) component values obtained by modeling the experimental Electrochemical Impedance Spectroscopy (EIS) data for samples after immersion in SBF solution for different durations.

\begin{tabular}{|c|c|c|c|c|c|c|}
\hline & $\operatorname{Rs}(\mathbf{o h m})$ & $\mathbf{R p}(\mathrm{ohm})$ & $\operatorname{CPE}\left(\operatorname{S.sec}^{\wedge} \mathbf{n}\right)$ & $\operatorname{Rs}(\mathbf{o h m})$ & $\mathbf{R p}(\mathbf{o h m})$ & $\operatorname{CPE}\left(\operatorname{S.sec}^{\wedge} n\right)$ \\
\hline \multicolumn{4}{|c|}{$15 \mathrm{~min}$} & \multicolumn{3}{|c|}{$24 \mathrm{~h}$} \\
\hline Homogenized & 44.4 & $7.555 \mathrm{E} 4$ & $1.179 \mathrm{E}-5$ & 71.40 & $1.372 \mathrm{E} 5$ & $1.682 \mathrm{E}-5$ \\
\hline 1P & 45.75 & $1.456 \mathrm{E} 5$ & $1.235 \mathrm{E}-5$ & 21.60 & $3.683 \mathrm{E} 5$ & $1.192 \mathrm{E}-5$ \\
\hline 1P-nFA & 47.83 & $2.102 \mathrm{E} 5$ & $1.751 \mathrm{E}-5$ & 39.22 & $1.672 \mathrm{E} 6$ & $6.237 \mathrm{E}-6$ \\
\hline 3P & 522.2 & $1.05 \mathrm{E} 5$ & $1.887 \mathrm{E}-5$ & 168.3 & $2.208 \mathrm{E} 5$ & $1.802 \mathrm{E}-5$ \\
\hline 3P-nFA & 42.83 & $2.745 \mathrm{E} 5$ & $6.04 \mathrm{E}-6$ & 73.11 & $3.948 \mathrm{E} 6$ & $1.285 \mathrm{E}-5$ \\
\hline \multicolumn{4}{|c|}{$118 \mathrm{~h}$} & \multicolumn{3}{|c|}{30 day } \\
\hline Homogenized & 55.97 & $8.594 \mathrm{E} 4$ & $1.913 \mathrm{E}-5$ & 52.82 & $4.388 \mathrm{E} 4$ & $4.49 \mathrm{E}-5$ \\
\hline $1 P$ & 124 & $7.456 \mathrm{E} 5$ & $1.073 \mathrm{E}-5$ & 47.85 & $2.802 \mathrm{E} 5$ & $1.250 \mathrm{E}-5$ \\
\hline 1P-nFA & 38.03 & $1.284 \mathrm{E} 6$ & $7.297 \mathrm{E}-6$ & 115.7 & $6.286 \mathrm{E} 5$ & $3.388 \mathrm{E}-5$ \\
\hline $3 P$ & 146.7 & $2.746 \mathrm{E} 5$ & $1.560 \mathrm{E}-5$ & 33.86 & $9.557 \mathrm{E} 4$ & $9.124 \mathrm{E}-5$ \\
\hline 3P-nFA & 61.05 & $1.846 \mathrm{E} 6$ & $1.2 \mathrm{E}-5$ & 40.57 & $8.511 \mathrm{E} 5$ & $1.33 \mathrm{E}-5$ \\
\hline
\end{tabular}




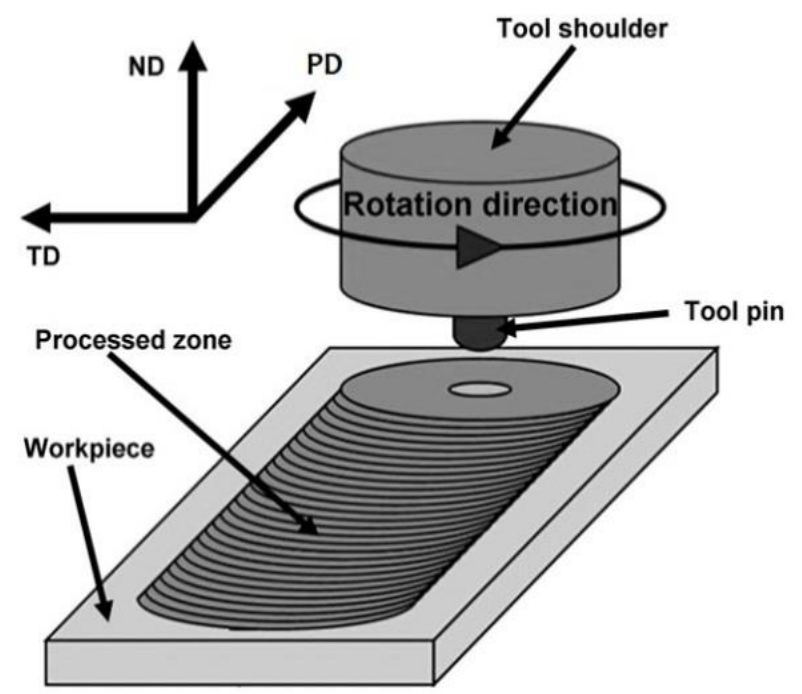

Fig. 1. Schematic figure of FSP processing [46]. 

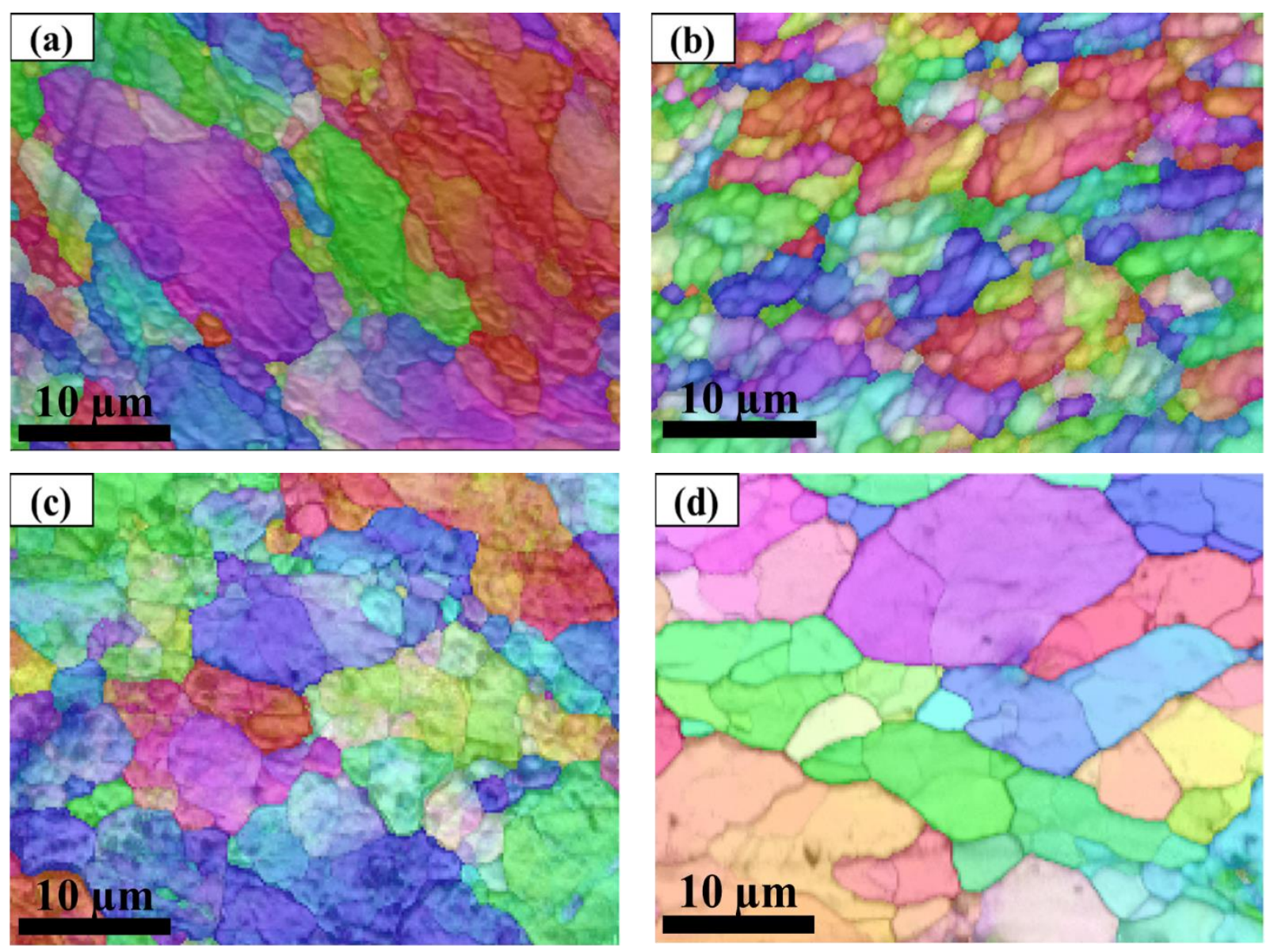

Fig. 2. Inverse pole figure maps of the stirring zone of the specimen processed through friction stir processing: (a) 1P-nFA, (b) 1P, (C) 3P-nFA, and (d) 3P (P stands for pass/passes). 

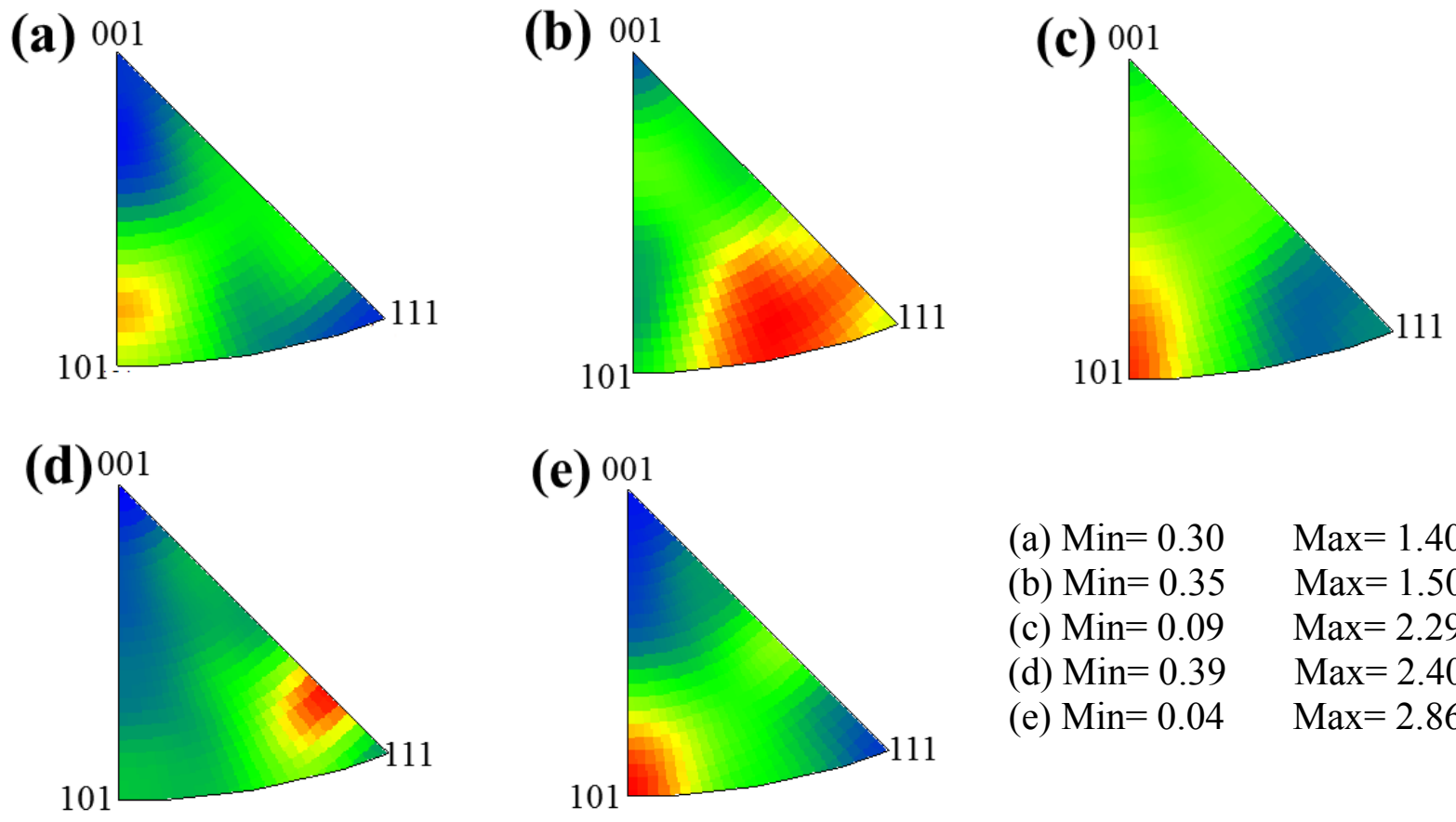
(a) $\operatorname{Min}=0.30 \quad \operatorname{Max}=1.40$
(b) $\operatorname{Min}=0.35 \quad \operatorname{Max}=1.50$
(c) $\operatorname{Min}=0.09 \quad \operatorname{Max}=2.29$
(d) $\operatorname{Min}=0.39 \quad \operatorname{Max}=2.40$
(e) $\operatorname{Min}=0.04 \quad \operatorname{Max}=2.86$

Fig. 3. Inverse pole figures of the TNTZ samples representing texture for (a) Homogenized, (b) 1PnFA (c) 1P, (d) 3P-nFA, (e) 3P sample, and the measured range of texture intensity. 

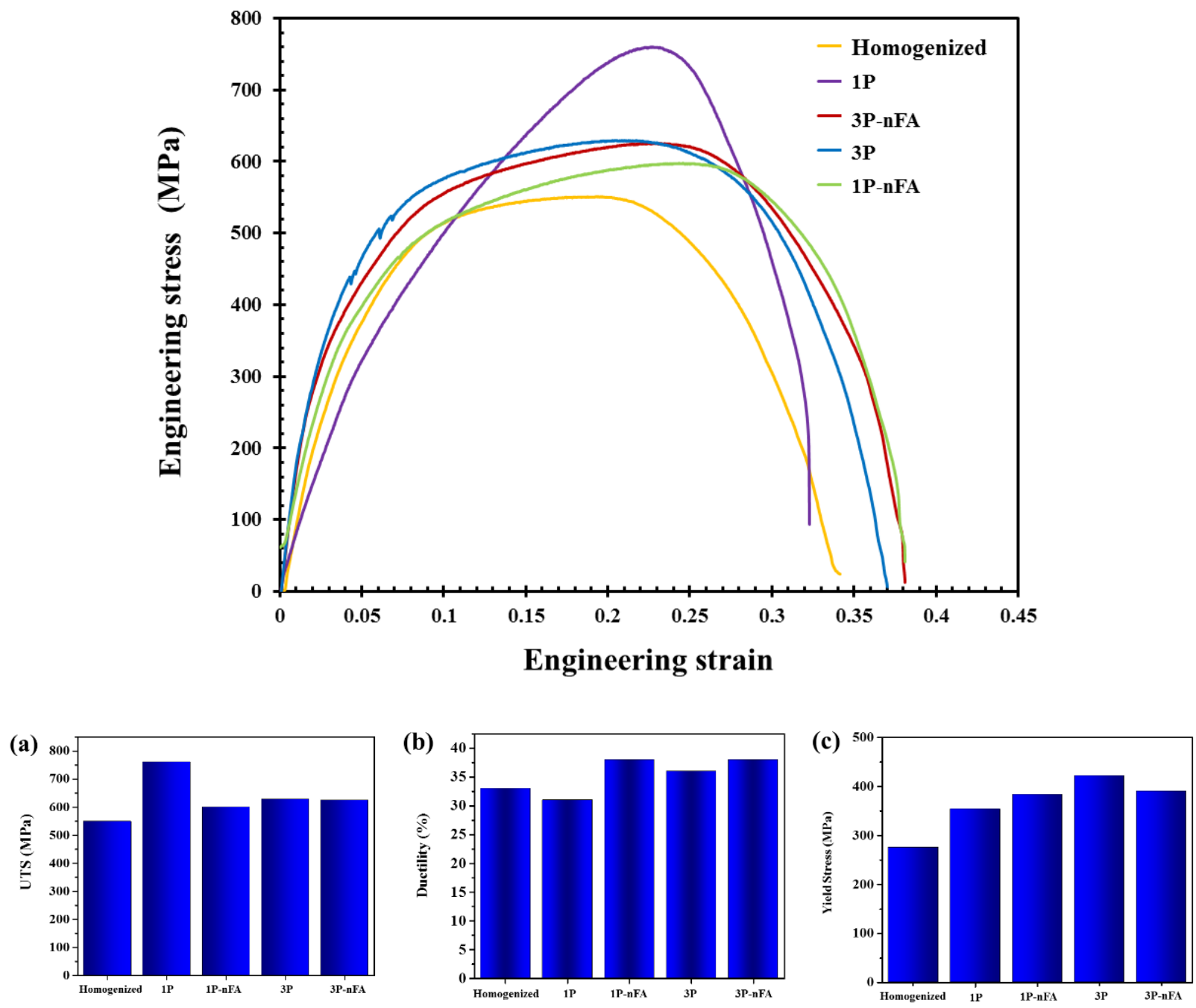

Fig. 4. Engineering stress versus engineering strain tensile curves for the homogenized and the FSPed specimens. Mechanical characteristics for homogenized, FSP and FSP-nFA Ti-29-Nb-13Ta-4.6Zr samples. (a) Ultimate tensile strength, (b) ductility and (c) yield stress. 


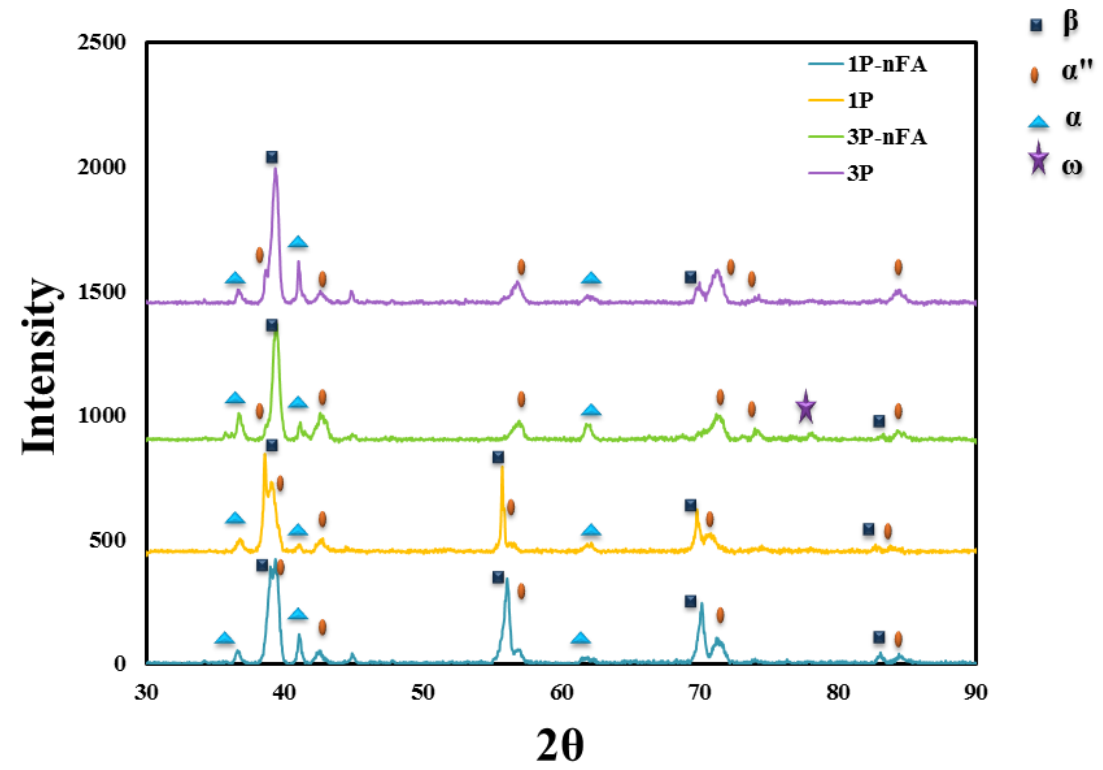

Fig. 5. X-ray diffraction patters of the FSPed samples. 


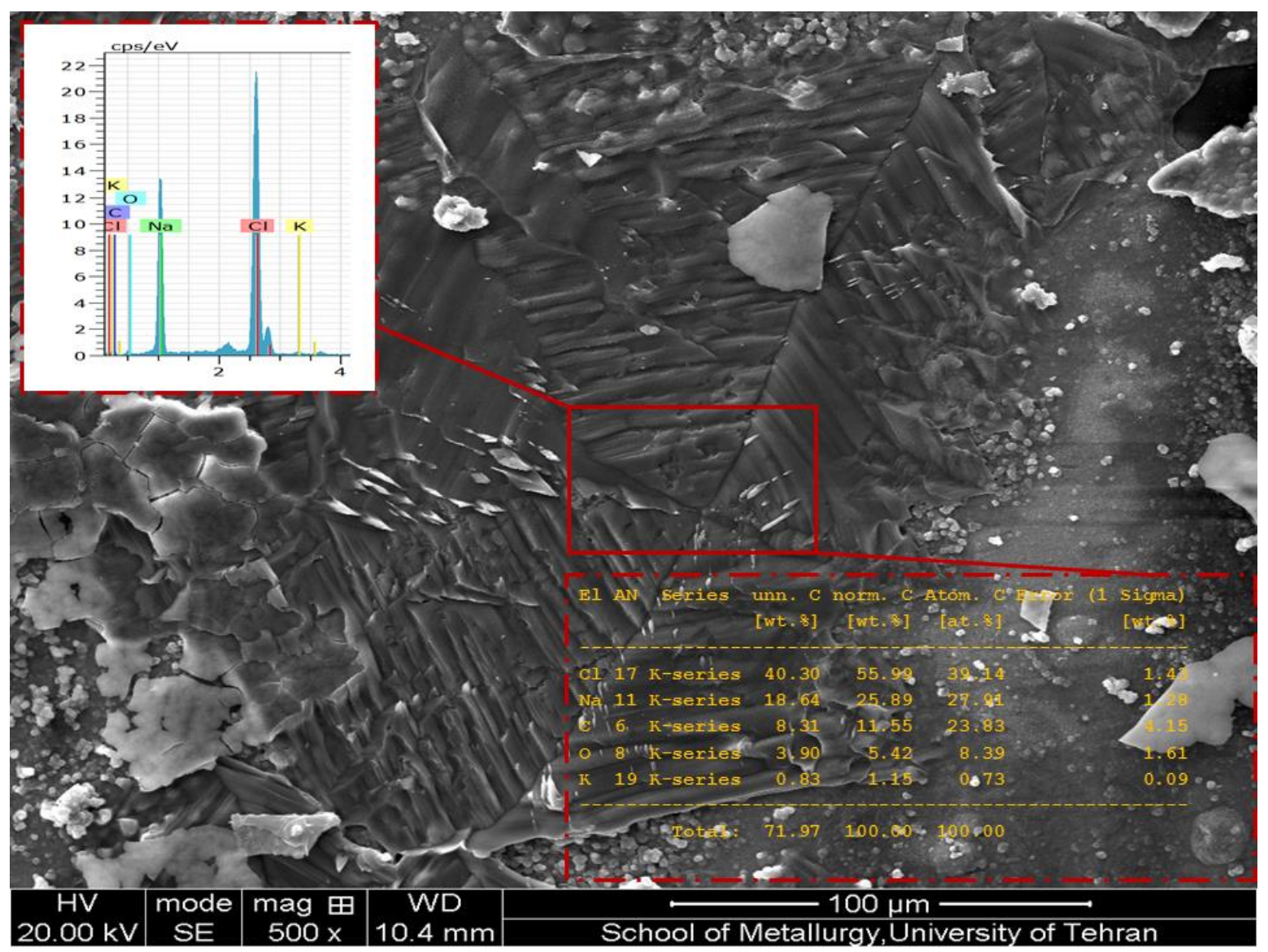

Fig. 6. The SEM micrograph and the corresponding EDS analysis of the homogenized sample after immersion in SBF for 30 days. 

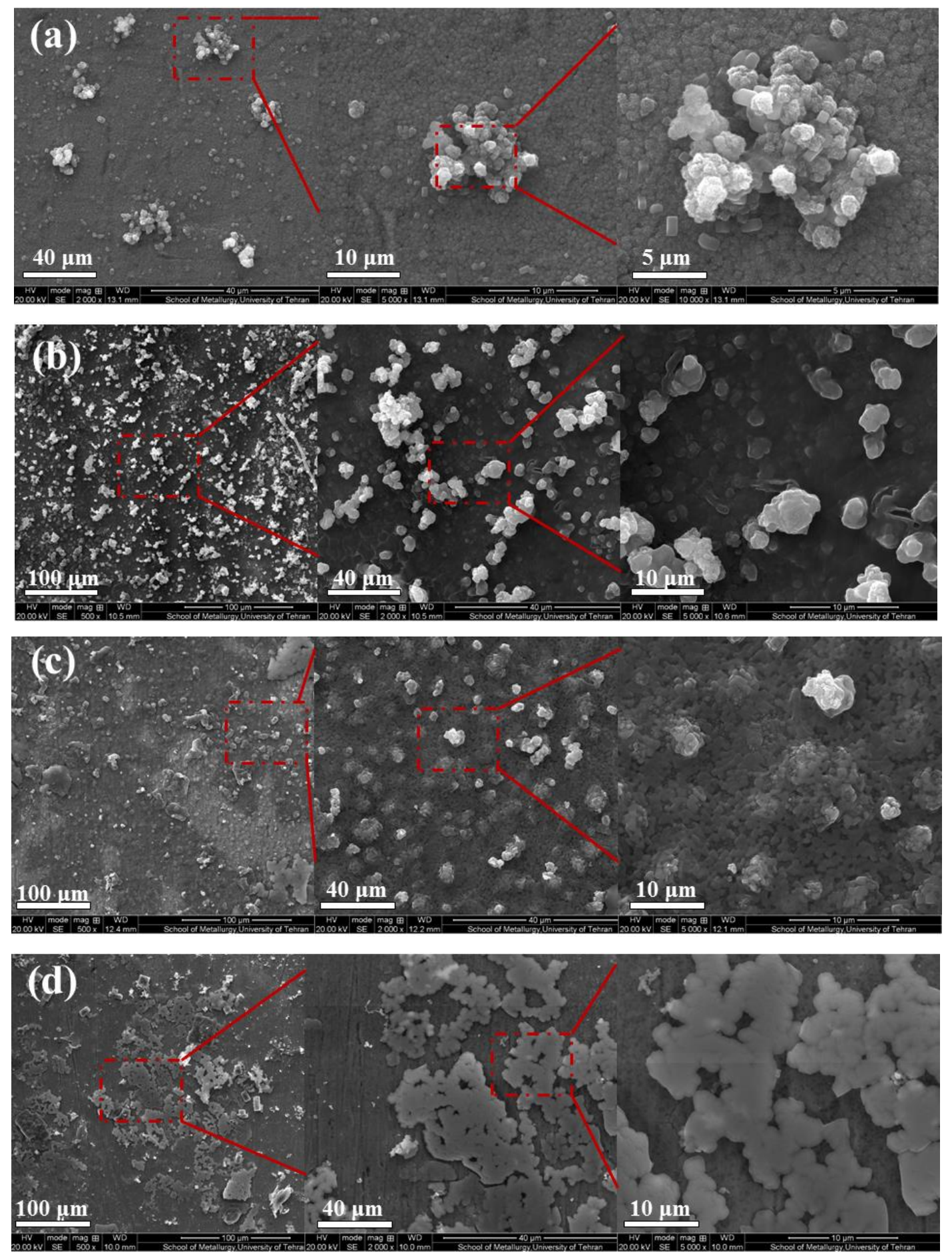

Fig. 7. The SEM micrograph of the processed specimens, (a) 1P-nFA, (b) 3P-nFA, (c) $1 \mathrm{P}$ and (d) 3P, after being immersed in SBF solution for 118 hours. 

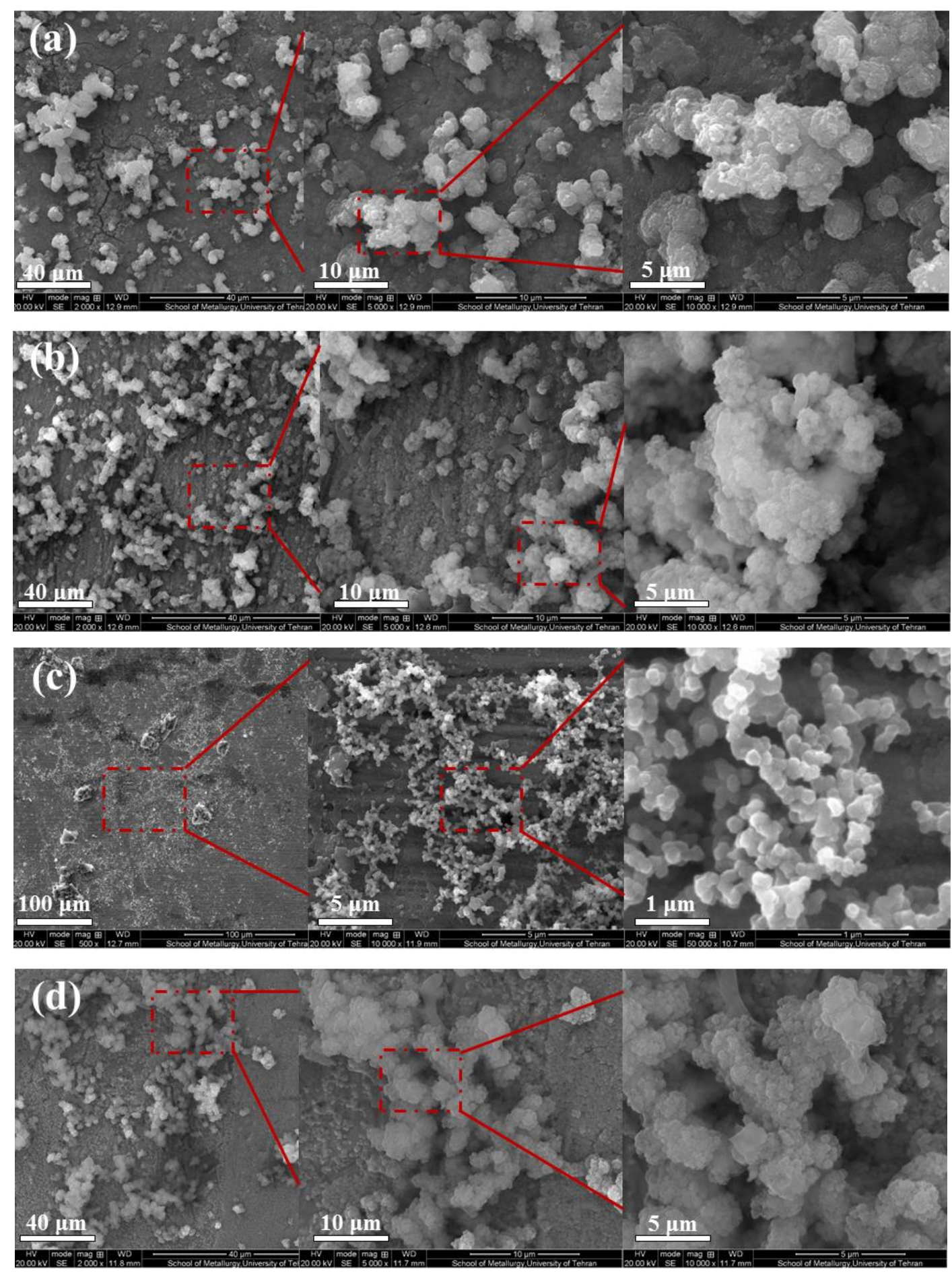

Fig. 8. The SEM micrograph of the processed specimens, (a) 1P-nFA, (b) 3P-nFA, (c) 1P and (d) 3P, after being immersed in SBF solution for 30 days. 


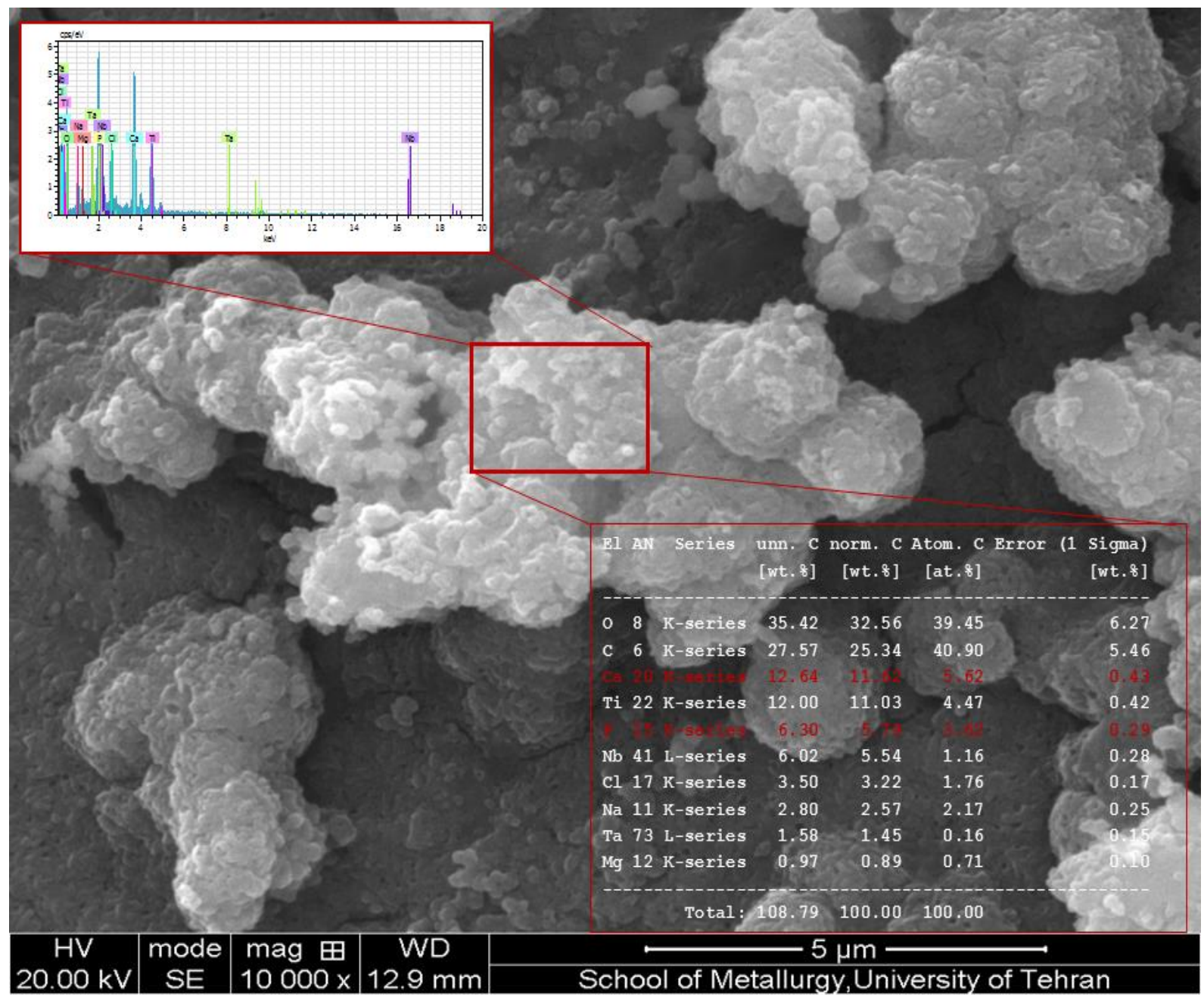

Fig. 9. The SEM micrograph and EDS analysis of the 1P-nFA sample after FSP and immersion in SBF solution for 30 days. 


\section{(a)}

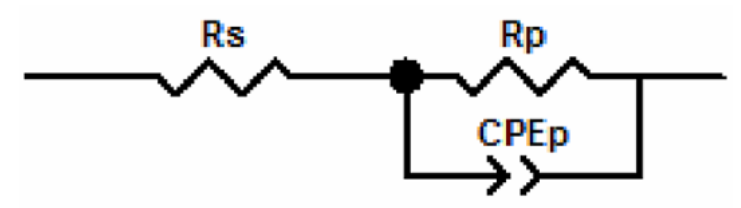

(b)

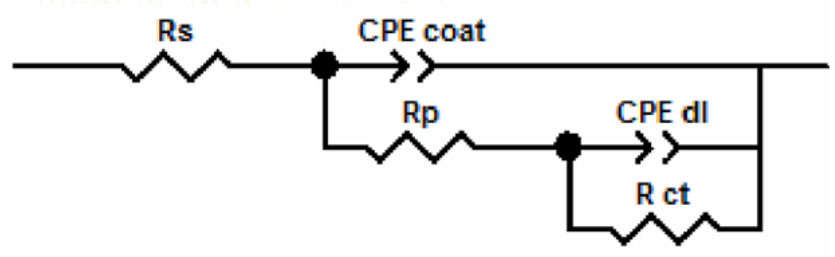

Fig. 10. The equivalent electrical circuit (EEC) without (a) and with (b) considering the possible formation of protective layer. 

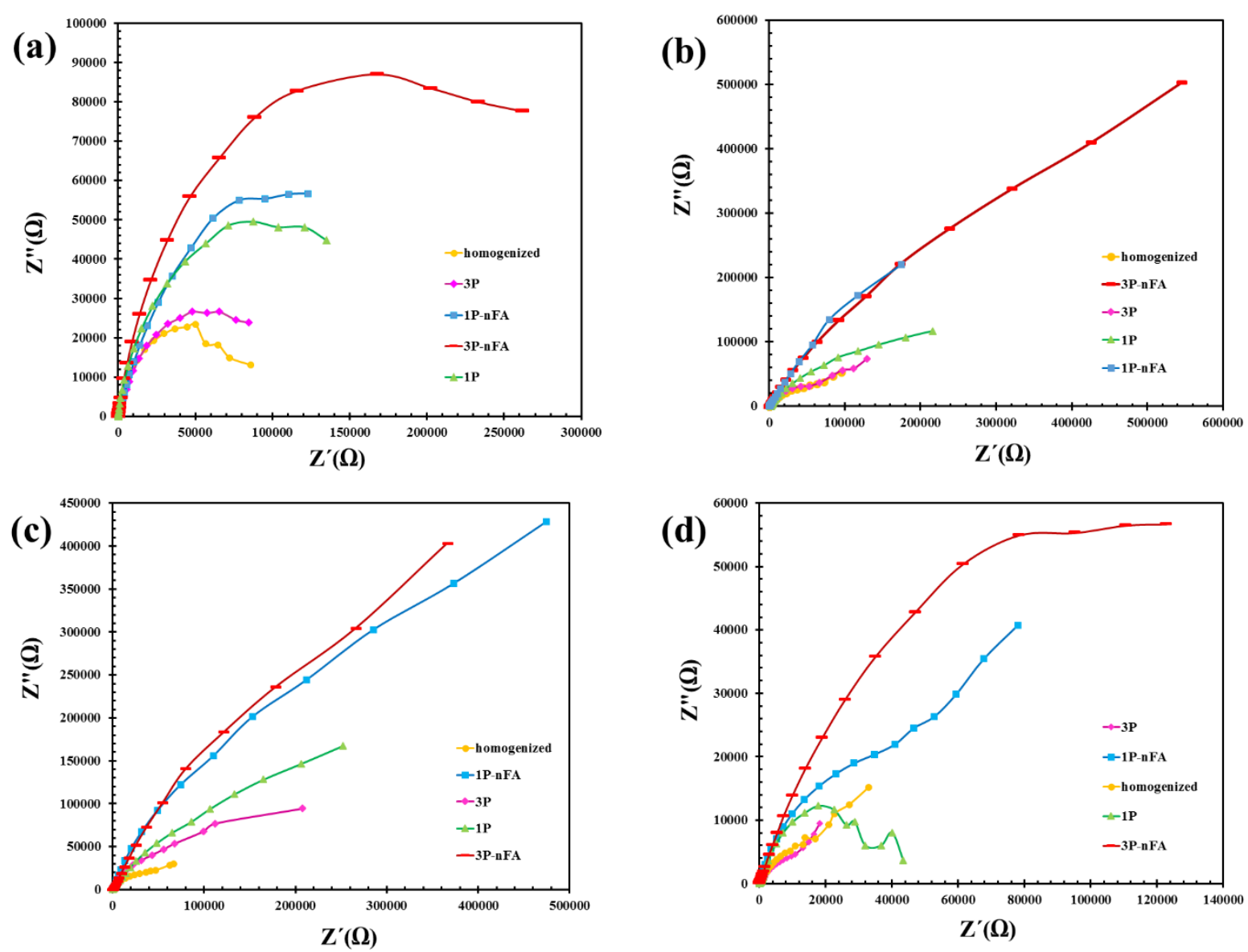

Fig. 11. The Nyquist representation of EIS spectra recorded in neutral SBF solution $\left(37^{\circ} \mathrm{C}\right)$ after Invitro test for the homogenized, FSP and FSP-nFA processed Ti-29-Na-13Ta-4.6Zr alloy, after immersion for (a) $15 \mathrm{~min}$, (b) $24 \mathrm{~h}$, (c) $118 \mathrm{~h}$ and (d) 30 days. 

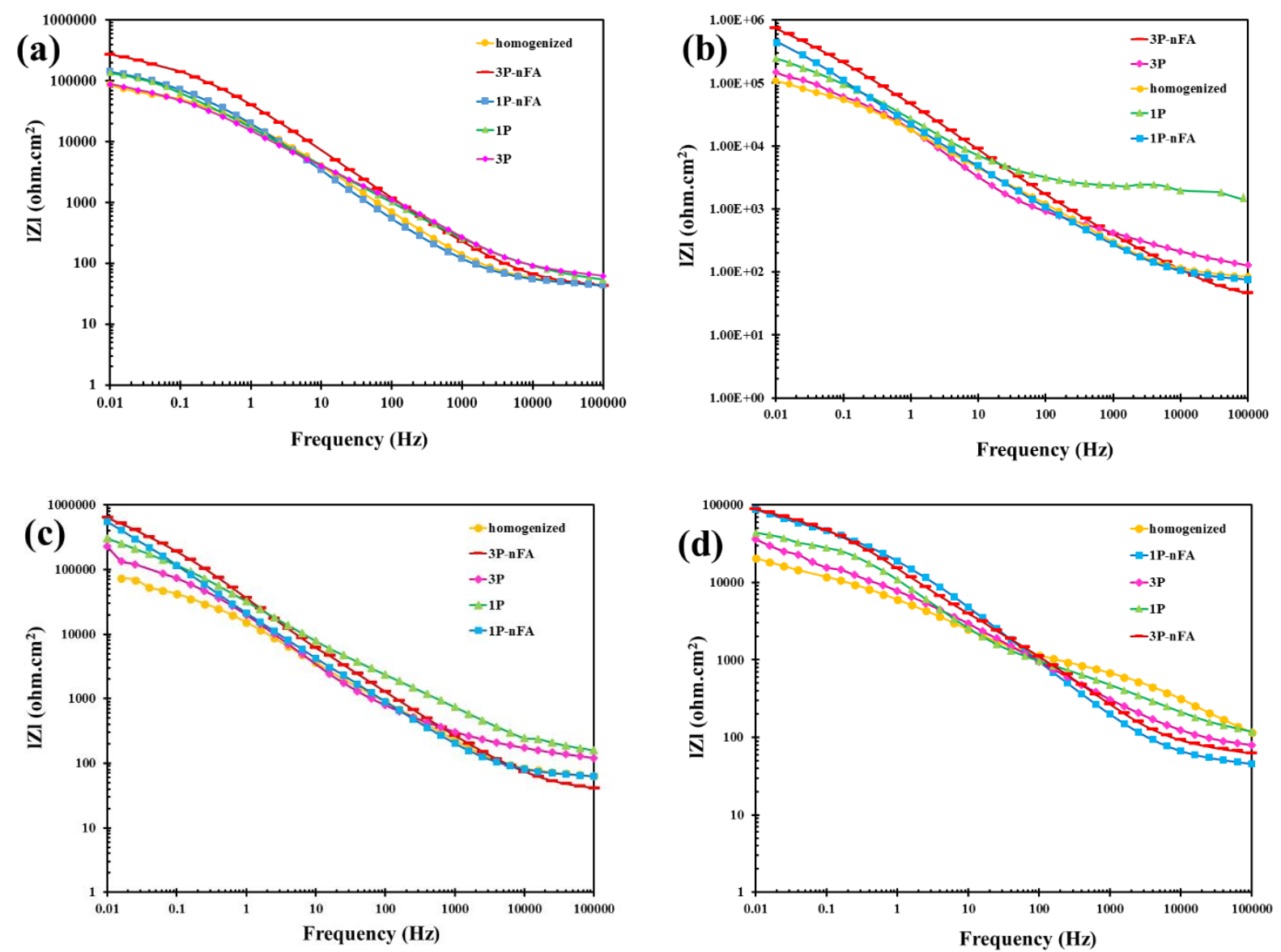

Fig. 12. The Bode representation of EIS spectra for the homogenized, FSP and FSP-nFA processed Ti29Na-13Ta-4.6Zr alloy after immersion in SBF solution for (a) $15 \mathrm{~min}$, (b) $24 \mathrm{~h}$, (c) $118 \mathrm{~h}$ and (d) 30 days. 

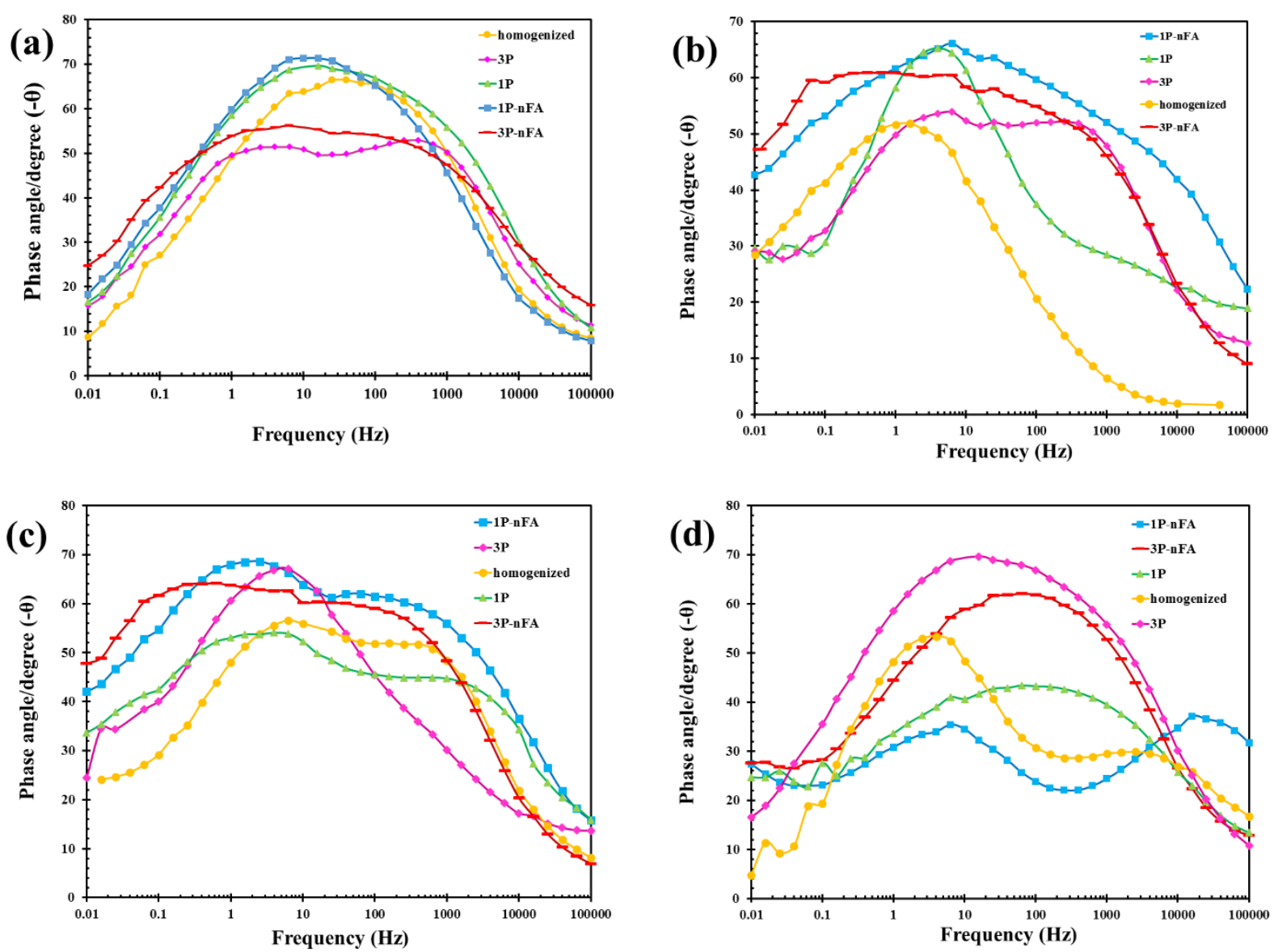

Fig. 13. The Phase representation of EIS spectra for the homogenized, FSP and FSP-nFA processed Ti29Na-13Ta-4.6Zr alloy after immersion for (a) $15 \mathrm{~min}$, (b) $24 \mathrm{~h}$, (c) $118 \mathrm{~h}$ and (d) 30 day. 


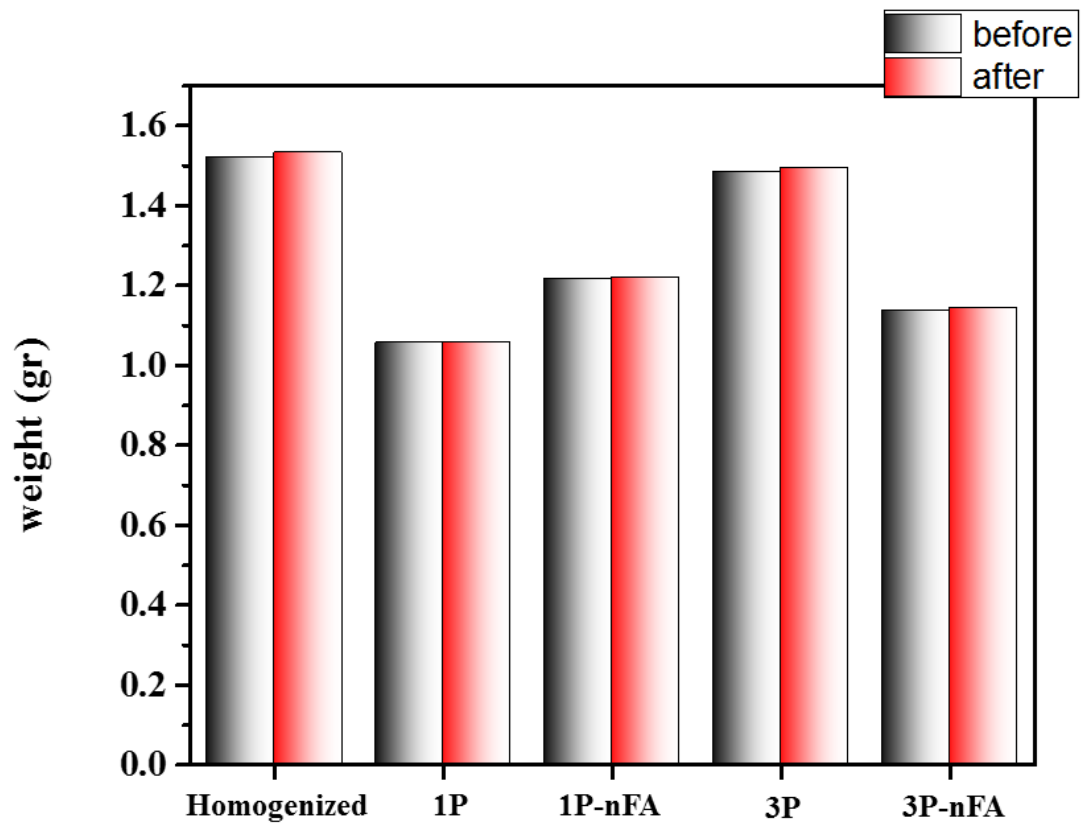

Fig. 14. The diagram of changed weight after 30 days immersion in SBF. 